\title{
Personal, social, and situational factors influencing the consumption of drinking water from arsenic-safe deep tubewells in Bangladesh
}

\author{
Hans-Joachim Mosler ${ }^{\mathrm{a}}$, Olivia R. Blöchliger ${ }^{\mathrm{b}}$, Jennifer Inauen ${ }^{\mathrm{a}, *}$

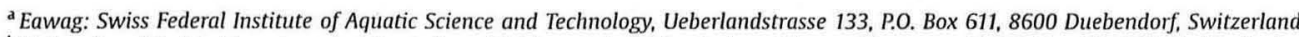 \\ ${ }^{b}$ University of Zurich, Department of Psychology, Division of Social Psychology, Binzmuehlestrasse 14, P.O. Box 15, 8050 Zurich, Switzerland
}

\author{
Keywords: \\ Bangladesh \\ Arsenic mitigation \\ Health-protective behaviour \\ Protection motivation theory \\ Theory of planned behaviour \\ Social acceptance \\ Social barriers
}

\begin{abstract}
A B S T R A C T
Naturally occurring arsenic in groundwater in Bangladesh poses a well-known public health threat. The aim of the present study is to investigate fostering and hindering factors of people's use of deep tubewells that provide arsenic-safe drinking water, derived from the Protection Motivation Theory and the Theory of Planned Behavior. Structured personal interviews were conducted with 222 households in rural Sreenagar, Bangladesh. Multiple linear regressions were carried out to identify the most influential personal, social, and situational behavior determinants. Data revealed that social factors explained greater variance in the consumption of drinking water from deep tubewells than did situational and personal factors. In an overall regression, social factors played the biggest role. In particular, social norms seem to strongly influence deep tubewell use. But also self-efficacy and the perceived taste of shallow tubewell water proved influential. Concurrently considering other important factors, such as the most mentioned response cost (i.e., time needed to collect deep tubewell water), we propose a socially viable procedure for installing deep tubewells for the extended consumption of arsenic-safe drinking water by the Bangladeshi population.
\end{abstract}

\section{Introduction}

Naturally occurring arsenic in groundwater is a major public health threat, affecting approximately 100 million people worldwide (Ahuja, 2008), in countries such as the U.S. (Shaw et al., 2005), Cambodia (Buschmann et al., 2007), and numerous others (Amini et al., 2008). The most arsenic-affected nation is Bangladesh, where, according to the latest estimations, approximately 20 million people are at risk of drinking arsenic-contaminated water above the national guideline of $50 \mu \mathrm{g} / \mathrm{l}$ (Johnston and Sarker, 2007). An even greater number of people is exposed to this hazard when applying the World Health Organization (WHO) guideline of $10 \mu \mathrm{g} / \mathrm{l}$.

The health impacts of excessive arsenic intake are diverse and known as arsenicosis. The earlier stages of arsenicosis are characterized by different forms of skin alterations. Later stages can include cancers of the skin, bladder, kidney, or lung (WHO, 2001). Also associated with the consumption of arsenic-contaminated water are cardiovascular diseases, diabetes, peripheral vascular diseases (e.g., gangrene WHO, 2001), and neurodevelopment

\footnotetext{
* Corresponding author. Tel.: +414482353 64; fax: +41448235028.

E-mail address: jennifer:inauen@eawag.ch (J. Inauen).
}

impairment in children (Wasserman et al., 2004). Men and the poor are most likely to suffer from arsenicosis (Hadi and Parveen, 2004), and the social and economic impacts of the disease are severe (Hassan et al., 2005).

To date, no cure for arsenicosis exists, although the beneficial effects of some therapeutic measures (e.g., vitamins) are being investigated (Smith et al., 2000). Preventing arsenic exposure by supplying safe water is thus the most vital mitigation approach.

\subsection{Arsenic mitigation in Bangladesh}

In Bangladesh in the 1970s, to diminish a cholera epidemic, millions of shallow tubewells were installed to tap groundwater, changing the main source of drinking water from surface water to groundwater. With decreased mortality rates resulting from waterborne diseases, the campaign was declared a success until the detection of the first arsenicosis cases in the 1990s, which were linked to excessive arsenic in the groundwater (Caldwell et al., 2003). Arsenic contamination in Bangladesh was soon recognized to be a major public health emergency (Atkins et al., 2007).

While considerable achievements have been made in arsenic mitigation since the problem's detection, the question arises as to why approximately $57 \%$ of the initially exposed Bangladeshi (Ahmed et al., 2006) remain at risk of drinking arsenic-contaminated water. 
Possible answers may be institutional shortcomings and scientific and technological indeterminacies such as the debate about the best mitigation measures (Atkins et al., 2007). Another possible reason could be the lack of knowledge on and consideration of people's acceptance and use of mitigation options. Of the natural sciencedominated research on arsenic mitigation, only a few have been social science studies, mostly concerned with people's knowledge and awareness of arsenic contamination, arsenicosis, and arsenic removal options and their socioeconomic correlates (Caldwell et al., 2003; Johnston and Sarker, 2007; Paul, 2004).

Of late, the issue of behavioral influence factors other than awareness has been attracting more attention. Research findings suggest that distance to the nearest safe well (Hoque et al., 2004; Opar et al., 2007), education (Opar et al., 2007), and social barriers for women (Hoque et al., 2004) are related to risk mitigation behavior. Additionally, the social acceptance of different mitigation measures has been assessed by some, and people have been shown to prefer deep tubewells, piped water supply (Hoque et al., 2004), and switching to arsenic-safe wells (Van Geen et al., 2002).

The abovementioned studies represent an important step towards an improved understanding of people's acceptance of mitigation options and the identification of health-protective behavior determinants. However, theory-based studies are mostly absent.

\subsection{The present study}

The aim of the present study is to address this research gap by investigating theory-based fostering and hindering factors of people's acceptance and use of technologies that provide arsenic-safe drinking water. As a mitigation option for our study, we chose deep tubewells because they have been the most frequently implemented safe water option in Bangladesh to date and have proven more sustainable with respect to operation and maintenance problems than other options (Kabir and Howard, 2007). Deep tubewells provide safe water by tapping deeper, arsenic-free aquifers. In contrast to shallow tubewells, building deep tubewells is quite costly. Therefore, deep tubewells are usually installed by an NGO or the government and have to be used by several families (Von Brömssen et al., 2007).

\subsubsection{Health-protective behavior}

Psychological research indicates that the use of a new drinking water technology always faces several barriers in everyday life (Altherr et al., 2008: Heri and Mosler, 2008; Moser and Mosler, 2008). These barriers can be grouped into three categories: personal, social, and situational behavior determinants. Some of these factors have been identified in different psychological theories such as the Protection Motivation Theory (Rogers and PrenticeDunn, 1997), the Theory of Planned Behavior (Ajzen, 1985), and the Health Action Process Approach (Schwarzer, 2008). For the present study, the Protection Motivation Theory was chosen as the major theoretical basis given its suitability for explaining a current behavior. In addition, social influence on people's health-protective behavior was included in compliance with Ajzen's Theory of Planned Behavior. Finally, two possible behavior determinants that proved influential in previous studies were also investigated: (a) money contributed for the deep tubewell's installation (WSP and UNICEF, 2007) and (b) whether the shallow tubewell was perceived as arsenic contaminated (Severtson et al., 2006). We classified the derived fostering and hindering factors into the categories of personal, social, and situational behavior determinants and, in accordance with the Protection Motivation Theory, assume the following relationships between these factors and deep tubewell use.
For personal factors, we suppose that, with increased (a) perceived severity of arsenicosis, (b) perceived vul nerability (likelihood of being affected by the health threat), (c) self-efficacy (confidence in the ability to prevent the health threat), (d) response-efficacy (perceived effectiveness of the behavior in preventing the health threat), and (e) fear of the health threat, (f) decreased response costs of the new behavior, $(g)$ increased behavior-enhancing personal experiences, $(\mathrm{h})$ increased awareness and (i) increased knowledge of arsenic contamination and arsenicosis, there will be an increased use of deep tubewells.

Regarding social factors, we assume that, with (a) increased use of deep tubewells by a person's significant others (descriptive norm), (b) the increased perception that they expect him or her to use deep tubewells (normative belief), (c) the tubewells' better reputation (injunctive norm), (d) greater social benefits of using deep tubewells, and (e) lower social response costs, the deep tubewells' use will increase.

Finally, for the situational factors, we assume that (a) lower situational response costs of using deep tubewells (e.g., distance to the deep tubewell) and (b) more behavior-enhancing prior experiences (e.g., taste of the water) will result in increased deep tubewell use. Furthermore, we suppose there will be increased use of deep tubewells by respondents who (c) perceive their shallow tubewell is arsenic contaminated and those who (d) contributed money to the deep tubewell's installation.

To test the proposed assumptions, structured personal interviews were conducted with households in rural Sreenagar, Bangladesh. The data was analyzed by multiple linear regressions.

The results of this study shall add to our understanding of the behavior determinants that need to be enhanced or diminished in order to increase people's acceptance and use of deep tubewells. The study of deep tubewells may also serve as an example for research on the acceptance and use of other mitigation options.

\section{Method}

A cross-sectional survey design was employed to assess the behavior determinants discussed above.

\subsection{Sample and procedures}

In January and February 2008, 222 randomly selected households of Sreenagar upazila (subdistrict) of the Munshiganj district, Bangladesh, took part in personal structured interviews. The participating villages were selected by the union council based on the arsenic level in the groundwater and the availability of deep tubewells. In total, the sampling pool consisted of approximately 12,600 households. These were selected by the random-route method (Hoffmeyer-Zlotnik, 2003), which means that the interviewers went to every fifth household on their way through the assigned area. The interviews were conducted with the household member responsible for the drinking water supply. No approached household refused the interview. Experienced interviewers from the Bangladeshi survey institute Data International conducted the survey after having received supplementary training by two psychology students of the University of Zurich (Switzerland), who also supervised the survey. Each interview required approximately one hour.

Of the 222 respondents, $70.3 \%$ were female, with a mean age of 39 years $(S D=12.2)$; $29.4 \%$ had never attended school; $25.7 \%$ had completed one to five years of schooling; $32.6 \%$ had completed six to 10 years, and $12.4 \%$ had completed a high school degree or higher education. The majority of interviewees were Muslim (93.7\%), with the remainder being Hindu. The mean number of household members was $5.5(\mathrm{SD}=2.3) ; 61 \%$ of the respondents were homemakers; $9 \%$ were self-employed or business owners; $7 \%$ worked in 
the agricultural sector; $6 \%$ were regularly employed; $4 \%$ were unemployed, and $7 \%$ had other occupations.

\subsection{Measures}

A structured questionnaire was specifically developed for this study. It contained a sociodemographic section and questions about water consumption and personal, social, and situational determinants of deep tubewell use. Some items were constructed following examples from previous studies: perceived severity, vulnerability, self-efficacy, and response-efficacy were formulated similarly to Martin et al. (2007), and a knowledge score was created in accordance with that employed by Paul (2004). The questionnaire was pre-tested in Bangladesh and then revised.

\subsubsection{Drinking water consumption}

The dependent variable of this study is the quantity of deep tubewell water used for drinking. To assess this, respondents were asked to estimate the number of pitchers they collected from different water sources each day. Sources offered were deep tubewell, shallow tubewell, dug well, rainwater, river or canal, pond, or other. From this information, the interviewers calculated the percentage of the total number of pitchers collected per household per day from the deep tubewell.

\subsubsection{Personal factors}

Perceived severity of arsenicosis was assessed with three items. Respondents were asked to rate how serious they perceived the personal negative consequences of arsenic contamination to be ( $1=$ not at all serious to $4=$ very serious) and how severely contracting arsenicosis would impact their social and economic life ( $1=$ not at all severely to $4=$ very severely). The scale was constructed by adding the values for the three items and dividing this sum by three. Cronbach's alpha for the severity scale reached a satisfactory 0.80 , indicating good reliability.

To measure perceived vulnerability to suffering from arsenicosis, respondents were asked to rate both their personal likelihood of contracting arsenicosis and the likelihood of household members contracting arsenicosis $(1=$ very likely to $4=$ not at all likely). Again, the values of the two items were summed and then divided by two. Reliability of the vulnerability scale was very good $(\alpha=0.95)$.

Self-efficacy in preventing arsenicosis was operationalized with respondents' ratings of their confidence in their ability to provide arsenic-safe water for their families and their general confidence in their ability to protect their families from arsenicosis $(1=$ not at all confident to 4 =very confident). The self-efficacy scale was also constructed by adding values for the two items and dividing the sum by two. Cronbach's alpha for this scale was very high $(\alpha=0.95)$.

Response-efficacy in preventing arsenicosis was assessed indirectly by respondents' estimation of how free from arsenic was the water they used from the deep tubewell $(1=$ not at all free to $4=$ totally free).

Furthermore, fear of contracting arsenicosis was measured by asking respondents to rate how afraid they are of suffering from arsenicosis $(1=$ not at all afraid to $4=$ very much afraid).

Personal response costs were operationalized by respondents' perceived expenditure of time to collect water from the deep tubewell ( 1 = very low to 4 =very high), their exhaustion due to collecting deep tubewell water, and the rating of their annoyance at sharing the deep tubewell with other people $(1=$ very low to $5=$ very high).

To measure personal experiences regarding the use of deep tubewells, respondents were asked to rate the extent of their experienced reservations about drinking deep tubewell and shallow tubewell water $(1=$ no reservations to $5=$ very many reservations) and to indicate the perceived hazardousness of the path to the deep tubewell $(1=$ very low to $5=$ very high $)$.

Participants' awareness of arsenic contamination was assessed by asking whether respondents were personally affected by arsenicosis and if they were acquainted with people affected by arsenicosis $(1=$ no, $2=$ yes $)$. Finally, knowledge of arsenic contamination and arsenicosis was measured by four items and integrated to a score, following the procedure in Paul (2004): respondents were asked whether they had heard of arsenic contamination (yes $=4$ points), what the sources of arsenic poisoning are (drinking arsenic-contaminated water $=4$ points; cooking with arsenic-contaminated water $=6$ points), what the symptoms of arsenic poisoning are (each correct answer $=2$ points), and how long it takes to develop symptoms (2-20 years $=4$ points). The score was calculated by adding all points, with a possible maximum of 32 points.

\subsubsection{Social factors}

Three different types of norms were assessed to measure social influence. For the descriptive norm, respondents were asked to indicate whether deep tubewells were used by their families or the members of their villages $(1=$ no, $2=$ yes $)$. The normative belief regarding the use of deep tubewells was assessed by agreement to the statement: 'My family members want me to get water from the deep tubewell' ( $1=$ not at all to $5=$ very much so). Similarly, the injunctive norm (i.e., the behavior's reputation) was measured by subjects' ratings of the statements 'I think positively about others using deep tubewells' and 'Others think negatively about people using deep tubewells' $(1=$ not at all to $5=$ very much $)$.

Furthermore, the social benefit of using deep tubewells was assessed by asking respondents whether they like to chat at the deep tubewell $(1=$ not at all to $5=$ very much $)$.

Finally, social response costs were measured with an open question that asked respondents to name any disadvantages of using deep tubewell water. Interviewees mentioned social costs, as well as a number of situational response costs. The social disadvantages included the location of the deep tubewell near a mosque, a school, or in a very crowded area, which makes it difficult for women to access the well, since in Bangladesh it is not socially acceptable for women to meet with men outside their families. These disadvantages were grouped into the single factor of social barriers for women: if one or more of these social disadvantages was mentioned by the respondent, this was coded as 2 (=yes), otherwise as $1(=$ no $)$.

\subsubsection{Situational factors}

Situational response costs were measured with the open item described above and additionally by seven structured items: (a) the time needed to collect water from the deep tubewell $(1=1-5 \mathrm{~min}$. to $6=26-30 \mathrm{~min}$., $7=>30 \mathrm{~min}$.), (b) respondents' perception of the waiting time at the deep tubewell as too long $(1=$ not at all to $5=$ very much), (c) the operability of the deep tubewell $(1=$ very bad to $5=$ very good), (d) if there are any limitations on using the deep tubewell and, more specifically ( $1=$ no, $2=$ yes), (e) whether there are seasonal limitations on using the deep tubewell (e.g., due to floods in the rainy season, $1=$ no, $2=y e s$ ), as well as (f) the laboriousness of collecting water from the deep tubewell compared to the shallow tubewell $(1=$ shallow tubewell is much more laborious to $5=$ deep tubewell is much more laborious), and $(\mathrm{g})$ the accessibility of arsenic-safe water $(1=$ very low to $5=$ very high $)$.

As prior experiences, respondents' beliefs about the healthiness ( 1 = very unhealthy to $5=$ very healthy $)$ and taste $(1=$ very bad to $5=$ very good) of deep tubewell and shallow tubewell water were measured. 
Furthermore, perceived arsenic contamination of the shallow tubewell was assessed by asking respondents how free from arsenic they thought the water from their shallow tubewell was $(1=$ no contamination to $4=$ very high $)$. Finally, respondents were asked to indicate whether they had contributed any money to the deep tubewell's installation $(1=$ no, $2=$ yes $)$.

\subsection{Data analysis}

Data was analyzed using SPSS 15.0. First, frequencies of all variables were computed. To make the display of frequencies comparable to that of the other variables, the scaled constructs of this study were categorized. However, for all further statistical procedures, the scaled form of these constructs was used. Perceived severity, vulnerability, and self-efficacy scales were each grouped into four categories (steps of 0.75 ): 1-1.75 (very low) to $3.25-4$ (very high). The knowledge score was divided into five categories from $0-7$ points (very low knowledge) to $24-32$ points (very high knowledge).

Second, correlations and multiple linear regressions were performed. Three separate multiple linear regressions were calculated to identify the most influential personal, social, and situational behavior determinants. Furthermore, a final model including all significant factors of the first three regressions was computed. The enter method was applied to insert predictor variables into regressions, since it was of interest to our study to investigate all hypothesized behavior determinants instead of testing a specific behavior theory. For all regression models, assumptions of no multicollinearity, normally distributed residuals, and independent errors were met.

\section{Results}

As much as $87.4 \%$ of the interviewees drank some deep tubewell water, and $62.2 \%$ drank some shallow tubewell water. While $36.9 \%$ of the respondents drank no water from the shallow tubewell, 14\% drank no water from the deep tubewell. More than half of the respondents drank $60 \%$ or more deep tubewell water, but only onefourth of the interviewed households consumed more than $60 \%$ shallow tubewell water.

\subsection{Descriptive statistics}

\subsubsection{Personal factors}

Survey data indicate that more than two-thirds of the respondents assessed the consequences of arsenicosis to be rather or very serious (perceived severity), while $38.8 \%$ of the interviewees believed there was a major risk of contracting arsenicosis (perceived vulnerability), 59.3\% felt confident in protecting themselves and their families from arsenicosis (self-efficacy), and nearly all respondents thought that using water from a deep tubewell was an efficient response for consuming arsenic-safe water (responseefficacy). Nevertheless, a large majority of the respondents (73.4\%) were afraid of contracting arsenicosis (fear). Regarding personal response costs of using deep tubewells, two-thirds of the respondents rated the time to collect water from a deep tubewell as high or very high, and $47 \%$ felt exhausted collecting water from the tubewells. However, sharing did not emerge as problematic for most interviewees: only $27.5 \%$ reported annoyance at sharing the deep tubewell with others.

\subsubsection{Social factors}

Almost $90 \%$ of the respondents stated that the deep tubewell was used by their family or other villagers. Half of the participants thought their family wanted them to collect water from a deep tubewell (normative belief). Data suggests that collecting water from a deep tubewell is socially a highly regarded behavior, as $95.7 \%$ of the respondents thought positively about others collecting water from deep tubewells, and $79.8 \%$ did not expect others to think negatively about somebody collecting deep tubewell water (injunctive norm).

As many as $37.9 \%$ of the respondents reported looking forward to having a chat at the deep tubewell (social benefit). Social barriers for women included traditional and religious limitations, the proximity of a deep tubewell to a mosque, and those situated in crowded public places: $25.2 \%$ of all interviewees mentioned at least one of these limitations (social response cost).

\subsubsection{Situational factors}

Almost all (207) respondents have shallow tubewells in front of their houses. Nearly all respondents spend fewer than 15 min collecting water from a shallow tubewell, while $39.1 \%$ spend more than 15 min collecting deep tubewell water, and nearly half of the interviewees (46.3\%) stated they sometimes have to wait too long at the deep tubewell.

In general, operability of the deep tubewell seems to be satisfactory; $76.9 \%$ of the respondents reported that the operability was good; more than half noted no limitations and $73 \%$ no seasonal limitations on using the deep tubewell. $42.9 \%$ found it more laborious collecting water from deep tubewells compared to shallow tubewells, and, consequently, three-quarters of the interviewees rated the accessibility to arsenic-safe water as low or very low.

The concentration of arsenic seems to be a critical issue in assessing the healthiness of water: $19 \%$ believed the shallow tubewell water was healthy (prior experiences), but nearly all respondents considered the deep tubewell water healthy.

\subsection{Correlations}

At first, all factors significantly associated with the dependent variable (i.e., the quantity of deep tubewell water used for drinking) were identified by means of bivariate correlations. Contrary to our assumptions, the following factors did not correlate significantly with the dependent variable and were therefore not included in the subsequent analyses: perceived severity, response-efficacy, fear, annoyance at sharing the deep tubewell, knowledge, the item 'family wants me to get water from the deep tubewell' (normative belief), seasonal limitations on using deep tubewells, the item 'laboriousness of collecting water from the deep tubewell versus the shallow tubewell,' and 'money contributed to building the deep tubewell'. Also, none of the respondents' socioeconomic characteristics (gender, education and age) were significantly correlated with the quantity of deep tubewell water used for drinking and were therefore not analyzed further.

\subsection{Regressions}

\subsubsection{Personal factors}

Four of the nine personal factors contributed significantly to the quantity of deep tubewell water used for drinking (see Table 1). As assumed, these findings indicate that more positive personal experiences concerning deep tubewell water (i.e., fewer reservations about drinking deep tubewell water) and more negative personal experiences with shallow tubewell water (i.e., more reservations about drinking shallow tubewell water) are associated with greater perceived self-efficacy, and lower response costs (i.e., the perception of time required being a waste of time) with increased use of deep tubewells. The model examining the personal aspects explains $34.6 \%$ of the total variance in the quantity of deep tubewell water used for drinking. 
Table 1

Simultaneous linear regression of personal factors on quantity of deep tubewell water used for drinking $(N=186)$.

\begin{tabular}{|c|c|c|c|c|c|}
\hline Personal factors & B & SE & $\beta$ & $t$ & $p$ (1-tailed) \\
\hline Perceived vulnerability to suffering from arsenicosis & 1.598 & 3.378 & 0.036 & 0.473 & 0.318 \\
\hline Self-efficacy in preventing arsenicosis & 10.408 & 3.715 & 0.232 & 2.802 & 0.003 \\
\hline Perceived expenditure of time to collect water from DTW & -6.723 & 2.793 & -0.187 & -2.407 & 0.009 \\
\hline Exhaustion due to collecting DTW water & 0.559 & 1.848 & 0.024 & 0.302 & 0.381 \\
\hline Reservations about drinking DTW water & -7.126 & 2.348 & -0.201 & -3.035 & 0.001 \\
\hline Reservations about drinking STW water & 7.001 & 1.934 & 0.263 & 3.620 & 0.000 \\
\hline Perceived hazardousness of path to DTW & -3.408 & 2.829 & -0.081 & -1.205 & 0.115 \\
\hline Personally affected by arsenicosis & -16.746 & 18.859 & -0.060 & -0.888 & 0.188 \\
\hline Acquaintance with people affected by arsenicosis & -9.742 & 7.166 & -0.088 & -1.359 & 0.088 \\
\hline
\end{tabular}

Note: adjusted $R^{2}=34.6 \%$. DTW $=$ deep tubewell, STW $=$ shallow tubewell.

\subsubsection{Social factors}

The regression evaluating the social variables (see Table 2) supports almost all of the proposed relationships between the social factors and deep tubewell use. Social barriers for women (social response costs) are an important factor impeding the use of deep tubewells. One factor identified for the enhancement of the consumption of deep tubewell water is the injunctive norm (i.e., thinking positively about others' use of deep tubewells and perceiving others as not thinking negatively about people using deep tubewells). Furthermore, the social benefit of chatting at the deep tubewell was found to be an indicator of increased use of deep tubewells. However, the strongest influence factor revealed by this regression model was whether the respondent's family used the deep tubewell for drinking (descriptive norm): if family members collect deep tubewell water, the respondent is more likely to also fetch water from the deep tubewell. In total, the social variables account for $47 \%$ variance in deep tubewell use. Since the descriptive norm (deep tubewell water used by family), due to its strong association with the dependent may act as a suppressor of other constructs' effects on deep tubewell use, we carried out an additional regression analysis without this factor. This analysis revealed the strongest influence on the dependent now to be the other measure of the descriptive norm: the use of deep tubewells by the respondents' neighbors $(\beta=0.440, p<0.001)$, which was an insignificant factor in the first regression. This model explained far less variance than the model including both measures of the descriptive norm (adj. $R^{2}=0.289$ ). In a third regression, we excluded both descriptive norm variables: this model was able to explain very little variance in deep tubewell use (adj. $\left.R^{2}=0.099\right)$.

\subsubsection{Situational factors}

The exploration of the situational aspects (see Table 3) confirmed the following assumptions: greater accessibility to arsenic-safe water and better taste of deep tubewell water means increased consumption of the water. However, lower quantities of deep tubewell water are consumed when more time is needed for its collection, and the shallow tubewell water is perceived as healthier and tastier. In total, the model containing situational factors explained a variance of $38.4 \%$ in the consumption of deep tubewell water.

\subsubsection{Overall regression}

In order to determine the relative importance of the personal versus social or situational factors, an overall model containing all the factors found to have a significant influence on deep tubewell water consumption was calculated (see Table 4). This regression analysis revealed that two social factors, namely the descriptive norm (deep tubewell used by family) and the injunctive norm (people thinking negatively about others' use of the deep tubewell), as well as one personal factor (self-efficacy) and one situational factor (taste of shallow tubewell water), remained as significant influences. The overall model accounts for 59\% variance, which means that the identified factors explain the consumption of deep tubewell water quite well.

\section{Discussion}

The aim of our study was to identify the factors that either foster or hinder the consumption of drinking water from arsenic-safe deep tubewells. Primarily, the potential factors were derived from the Protection Motivation Theory (Rogers and Prentice-Dunn, 1997) and grouped into personal, social, and situational factors.

\subsection{Summary and interpretation of results}

To sum up, interview data revealed that social factors explain more variance $(47 \%)$ than either situational $(38.4 \%)$ or personal factors (34.6\%) in the consumption of drinking water from deep tubewells. In the overall regression, social factors had the greatest impact; in particular, social norms (injunctive and descriptive norms) seem to strongly influence the use of deep tubewells. This is in line with findings on other health-protective behaviors: for example, Fekadu and Kraft's (2002) study revealed that social norms were more influential than personal factors in explaining intentions to use contraceptive methods by Ethiopian women. Nevertheless, the other relevant influences should not be disregarded because they give additional hints for interventions that may increase the use of deep tubewells.

Three response costs (social barriers for women, time needed, and perceived expenditure of time to collect deep tubewell water) and one benefit of deep tubewell use (liking to chat at the deep

Table 2

Simultaneous linear regression of social factors on quantity of deep tubewell water used for drinking $(N=178)$.

\begin{tabular}{|c|c|c|c|c|c|}
\hline Social factors & B & SE & $\beta$ & $t$ & $p$ (1-tailed) \\
\hline DTW used by family (descriptive norm) & 65.641 & 8.528 & 0.568 & 7.697 & 0.000 \\
\hline DTW used by villagers (descriptive norm) & 10.287 & 9.824 & 0.076 & 1.047 & 0.148 \\
\hline Think positively about others using DTWs & 9.819 & 3.441 & 0.161 & 2.853 & 0.002 \\
\hline Others think negatively about people using DTWs & -6.127 & 1.861 & -0.186 & -3.292 & 0.001 \\
\hline Like to chat at the DTW (social benefit) & 3.619 & 1.505 & 0.139 & 2.405 & 0.009 \\
\hline Social barriers for women (response cost) & -11.029 & 5.002 & -0.126 & -2.205 & 0.014 \\
\hline
\end{tabular}

Note: adjusted $R^{2}=47.0 \%$. DTW $=$ deep tubewell. 
Table 3

Simultaneous linear regression of situational factors on quantity of deep tubewell water used for drinking $(N=149)$.

\begin{tabular}{|c|c|c|c|c|c|}
\hline Situational factors & B & SE & $\beta$ & $t$ & $p$ (1-tailed) \\
\hline Time needed to collect DTW water & -6.723 & 2.140 & -0.296 & -3.142 & 0.001 \\
\hline Perception of waiting-time at DTW as too long & 0.566 & 2.233 & 0.023 & 0.253 & 0.400 \\
\hline Operability of DTW & 1.597 & 3.283 & 0.040 & 0.486 & 0.314 \\
\hline Limitations on using DTW & 4.776 & 5.973 & 0.063 & 0.800 & 0.213 \\
\hline Accessibility to arsenic-safe water & 8.181 & 3.820 & 0.205 & 2.141 & 0.017 \\
\hline Healthiness of DTW water & 7.401 & 5.261 & 0.115 & 1.407 & 0.081 \\
\hline Healthiness of STW water & -11.665 & 3.501 & -0.315 & -3.332 & 0.001 \\
\hline Taste of DTW water & 6.578 & 3.776 & 0.140 & 1.742 & 0.042 \\
\hline Taste of STW water & -8.449 & 3.006 & -0.244 & -2.811 & 0.003 \\
\hline Perceived arsenic contamination of STW & 1.050 & 4.002 & 0.023 & 0.262 & 0.397 \\
\hline
\end{tabular}

Note: adjusted $R^{2}=38.4 \%$. DTW = deep tubewell, STW = shallow tubewell.

tubewell) were identified as influencing factors. Further, the taste of the water from both types of tubewells, the personal factors of experienced reservations about drinking deep and shallow tubewell water, perceived healthiness of shallow tubewell water, selfefficacy, and accessibility to arsenic-safe water influenced the use of deep tubewells.

That social factors play a decisive role is not surprising because social and cultural norms are highly valued in the Bangladeshi society, with the family at its core (Anderson and Eswaran, 2009). Along with this societal structure, family and neighbor behavior has been revealed as the most crucial indicator of a respondent's own use of deep tubewells. Hence, social norms have a strong influence on individual behavior, a result that replicates findings from studies on other health-protective behaviors in other parts of the world (Altherr et al., 2008; Heri and Mosler, 2008; Graf et al., 2008; Moser and Mosler, 2008). The results of this study indicate that prevalent social norms encourage the use of deep tubewells: the attitude of the respondents and the perceived attitude of significant others are predominantly favorable. Thus, the reputation of using deep tubewells seems to be good and socially well accepted. This is consistent with the findings of Hoque et al. (2004) and Van Geen et al. (2002) that switching to arsenic-safe wells is a very popular arsenic mitigation option in Bangladesh.

The common reputation of deep tubewell use is good, but only half of the interviewees believed their family members wanted them to use the deep tubewell. What reasons lead to the gap between a positive attitude towards the use of deep tubewells and family members' reservations about deep tubewell use? Van Geen et al. (2002) pointed out that women are expected to not leave the homestead unaccompanied, and Hoque et al. (2004) found that social barriers for women influence arsenic mitigation behavior. These findings are supported by the present data: one-quarter of all interviewees mentioned social barriers for women decrease their use of deep tubewells. These barriers can be grouped into relative and absolute obstacles: some women are permitted to use deep tubewells on the condition they do not talk to men, whereas some women are not allowed to leave the homestead at all, due to traditional religious practices (Anderson and Eswaran, 2009). Many respondents reported women often felt harassed if they used the deep tubewell.

The most mentioned response cost was the time needed to collect deep tubewell water. This confirms the findings of Van Geen et al. (2002) and Hoque et al. (2004), who found that the use of deep tubewells is related to the distance to the well. In addition, Van Geen et al. (2002) reported that women collect water an average of 2.4 times a day, indicating that the time needed to collect deep tubewell water gets cumulated during the day. The single behavior-influencing benefit of deep tubewell use identified was meeting people at the deep tubewell and having a chat. Once again, this emphasizes the importance of social aspects.

The significant effect of self-efficacy means that people confident in their ability to carry out the protective behavior perform this behavior to a greater extent than non-confident people. The finding that self-efficacy is an important determinant of health-protective behavior confirms convergent evidence from past research (e.g., Floyd et al., 2000).

The prior experiences "good taste" in combination with perceived healthiness of shallow tubewell water impedes the consumption of deep tubewell water. This is consistent with Severtson et al. (2006), who found that personal experience (perceived water quality) mitigated the influence of communicated test results and safety standards (external sources) on reducing arsenic exposure. This means that when people perceive their water as being of good quality, they will not change to an alternative source.

Table 4

Simultaneous linear regression of all significant factors from previous regressions on quantity of deep tubewell water used for drinking $(N=176)$.

\begin{tabular}{|c|c|c|c|c|c|}
\hline All previously significant factors & B & SE & $\beta$ & $t$ & $p(1$-tailed $)$ \\
\hline Self-efficacy in preventing arsenicosis & 7.885 & 3.241 & 0.176 & 2.433 & 0.008 \\
\hline Perceived expenditure of time to collect water from DTW & -1.239 & 3.110 & -0.034 & -0.399 & 0.345 \\
\hline Reservations about drinking DTW water & -2.757 & 2.159 & -0.078 & -1.277 & 0.102 \\
\hline Reservations about drinking STW water & 2.227 & 1.938 & 0.084 & 1.150 & 0.126 \\
\hline DTW used by family (descriptive norm) & 46.969 & 7.770 & 0.406 & 6.045 & 0.000 \\
\hline Think positively about others using DTWs & 3.318 & 3.536 & 0.054 & 0.938 & 0.175 \\
\hline Others think negatively about people using DTWs & -4.379 & 2.162 & -0.133 & -2.026 & 0.022 \\
\hline Like to chat at the DTW (social benefit) & 1.867 & 1.639 & 0.072 & 1.139 & 0.128 \\
\hline Social barriers for women (response cost) & -5.084 & 5.142 & -0.058 & -0.989 & 0.162 \\
\hline Time needed to collect DTW water & -2.321 & 1.908 & -0.102 & -1.216 & 0.113 \\
\hline Accessibility to arsenic-safe water & 3.545 & 3.219 & 0.089 & 1.101 & 0.136 \\
\hline Healthiness of STW water & -3.983 & 3.008 & -0.108 & -1.324 & 0.094 \\
\hline Taste of DTW water & 1.913 & 2.823 & 0.041 & 0.678 & 0.250 \\
\hline Taste of STW water & -5.964 & 2.349 & -0.172 & -2.538 & 0.006 \\
\hline
\end{tabular}

Note: adjusted $R^{2}=59.0 \%$. DTW $=$ deep tubewell, STW $=$ shallow tubewell. 


\subsection{Limitations of the study and further research}

In future studies some of our variables should be improved in their conceptualization. Paul's (2004) instrument we used to assess knowledge did not discriminate between awareness and knowledge. A differentiation of the two concepts would provide more clarity. Our measure of awareness, furthermore, was about the experience with illness but should ideally be formulated as being aware of or having heard of a threat (Weinstein, 1988). Also, the distinction between normative belief and injunctive norm may not be as clear as we suggested and should be investigated more thoroughly. Finally, the difference between self-efficacy and response-efficacy should be made more explicit:, conceptualizing self-efficacy as the control over the behavior itself and response-efficacy as the control over outcomes or events (Ajzen, 2002; Lam, 2006).

Factors such as knowledge, awareness, fear, vulnerability, and severity unexpectedly revealed no effects on health-protective behavior, which may be due to the fact that our sample displayed high values in these variables. Therefore, for a population not so aware of the health threat, there might be an effect on behavior. Further, the results reveal possible dependencies between the independent variables, but in the absence of a usable theoretical model, no causal model structure can be tested. We hope that the presented work can serve as a basis for proposing a causal model that can be tested with structural equation modeling.

One of the next steps would be to implement a field experiment to test the procedure for enhancing the use of deep tubewells proposed below for its feasibility and usefulness. Different measures should be tested for their effectiveness and, as a criterion variable, the extent of the sample's deep tubewell water consumption should be employed.

Finally, the question regarding generalizability of the results of the present study remains. Are the identified factors relevant to arsenic mitigation options other than deep tubewells, or even to other health-protective behaviors? As previously mentioned, for some factors (e.g., social factors), studies indicate the importance of the present factors for other health-protective behaviors (Altherr et al., 2008; Heri and Mosler, 2008; Graf et al., 2008; Moser and Mosler, 2008). However, further research regarding different mitigation options, preferably in different regions of Bangladesh and other parts of the world, is needed to develop a more comprehensive understanding of water-related health-protective behavior.

\subsection{Conclusions and implications for practice}

The fact that knowledge, awareness, and perceived vulnerability and severity did not show any influence on the use of deep tubewells does not mean these factors are not important. Rather, we distinguish these factors as preconditions for any behavior in the health sector.

Deep tubewells seem to be a viable and well-accepted arsenic mitigation option. This implies that the emphasis of intervention programs should not focus mainly on the acceptance of deep tubewells, but more on their increased use. At the core of any promotion program for the use of deep tubewells, social interventions should be applied. First, the whole family, but also neighbors need to be convinced, as this is where the greatest influence is found. Furthermore, people's reservations have to be taken seriously, especially the social barriers for women, together with improved accessibility to the deep tubewells. Combining these issues with the hindering factor of time required to collect water, the following procedure for installing new deep tubewells is recommended.

First, one should plan to install several tubewells for a single village rather than a single well. This procedure allows the distribution of the tubewells at an optimal distance for most households. However, geometry should not be the main criterion, as social geometry is more important. Therefore, the optimal position of the deep tubewells should be discussed and decided upon with the villagers' participation. With regard to social barriers for women, enclosing the location with walls or screens could be a solution. Furthermore, special opening hours of the deep tubewells, for men and woman separately, may be helpful, with the added benefit of providing an opportunity for women's social interaction. Most importantly, deep tubewells should never be constructed in front of a mosque or in crowded public places. In a next step, social influence strategies should be applied both at the family and the village level, in order to establish social norms favoring the use of deep tubewells. A possible approach may be to identify and target the opinion leader (Rogers, 2003: Mosler and Martens, 2008) in each extended family. Once convinced, the use of deep tubewells should disseminate from the opinion leader, who serves as a social model (Bandura, 1977) for other members of the family. Similarly, opinion leaders at the village level (i.e., well-respected community members or religious leaders) should be convinced to use the deep tubewells. Thereby, the development of an injunctive norm for deep tubewell use can be enhanced.

Convincing people to use the deep tubewells may focus on the confidence that one can act adequately to prevent arsenicosis by consuming deep tubewell water and that one is not helpless when faced with this threat. Important issues also include the taste and healthiness of shallow tubewell water compared to deep tubewell water. It should be clearly demonstrated that shallow tubewell water is not at all healthy (which is sometimes done by painting these pumps red; see Caldwell et al., 2006), and the good taste and healthiness of the deep tubewell water should be emphasized.

\section{References}

Ahmed, M.E. Ahuja, S., Alauddin, M., Hug, S.J., Lloyd, J.R, Pfaff, A., et al., 2006 Ensuring safe drinking water in Bangladesh. Science 314, 1687-1688.

Ahuja, S., 2008. Arsenic Contamination of Groundwater: Mechanism, Analysis, and Remediation. John Wiley and Sons, Hoboken.

Ajzen, I., 1985. From intentions to actions: a theory of planned behaviour. In: Kuhl, J., Beckmann, J. (Eds.), Action Control: From Cognition to Behaviour. Springer, Berlin, pp. 11-39.

Ajzen, 1., 2002. Perceived behavior control, self-efficacy, locus of control, and theory of planned behavior. Journal of Applied Social Psychology 32. 665-683.

Altherr, A.-M., Mosler, H.-J., Tobias, R., Butera, F., 2008. Attitudinal and relational factors predicting the use of solar water disinfection: a field study in Nicaragua. Health Education and Behavior 35, 207-220.

Amini, M., Abbaspour, K., Berg, M., Winkel, L., Hug, S., Hoehn, E., et al., 2008. Statistical modeling of global geogenic arsenic contamination in groundwater. Environmental Science and Technology 42, 3669-3675.

Anderson, S., Eswaran, M., 2009. What determines female autonomy? Evidence from Bangladesh. Journal of Development Economics 90, 179-191.

Atkins, P., Hassan, M., Dunn, C., 2007. Environmental irony: summoning death in Bangladesh. Environment and Planning A 39, 2699-2714.

Bandura, A., 1977. Social Learning Theory. Prentice Hall, Englewood Cliffs, NJ.

Buschmann, J., Berg, M., Stengel, C., Sampson, M.L., 2007. Arsenic and manganese contamination of drinking water resources in Cambodia: coincidence of risk areas with low relief topography. Environmental Science and Technology 41, 2146-2152.

Caldwell, B.K., Caldwell, J.C., Mitra, S.N., Smith, W., 2003. Searching for an optimum solution to the Bangladesh arsenic crisis. Social Science and Medicine 56, 2089-2096.

Caldwell, B.K., Smith, W.T., Lokuge, K., Ranmuthugala, G., Dear, K., Milton, A.H., et al., 2006. Access to drinking-water and arsenicosis in Bangladesh. Journal of Health, Population, and Nutrition 24, 336-345 
Fekadu, Z., Kraft, P., 2002. Expanding the theory of planned behaviour: the role of social norms and group identification. Journal of Health Psychology 7, 33-43.

Floyd, D.L., Prentice-Dunn, S., Rogers, R.W., 2000. A meta-analysis of research on protection motivation theory. Journal of Applied Social Psychology 30 $407-429$.

Graf, J., Meierhofer, R., Wegelin, M., Mosler, H.-J., 2008. Water disinfection and hygiene behaviour in an urban slum in Kenya: impact on childhood diarrhoe and influence of beliefs. International Journal of Environmental Health Research 18, 335-355.

Hadi, A., Parveen, R., 2004. Arsenicosis in Bangladesh: prevalence and socioeconomic correlates. Public Health 118, 559-564.

Hassan, M.M., Atkins, P., Dunn, C., 2005. Social implications of arsenic poisoning in Bangladesh. Social Science and Medicine 61, 2201-2211.

Heri, S., Mosler, H.-J., 2008. Factors affecting the diffusion of solar water disinfection: a field study in Bolivia. Health Education and Behavior 35, 541-560.

Hoffmeyer-Zlotnik, J.H.P., 2003. New sampling designs and the quality of data. In: Ferligoj, A., Mrvar, A. (Eds.), Developments in Applied Statistics. FDV, Methodoloski zvezki, Ljubljana, pp. 205-217.

Hoque, B.A., Hoque, M.M., Ahmed, T., Islam, S., Azad, A.K., Ali, N., et al., 2004 Demand-based water options for arsenic mitigation: an experience from rural Bangladesh. Public Health 118, 70-77.

Johnston, R.B., Sarker, M.H., 2007. Arsenic mitigation in Bangladesh: national screening data and case studies in three upazilas. Journal of Environmental Science and Health, Part A 42, 1889-1896.

Kabir, A., Howard, G., 2007. Sustainability of arsenic mitigation in Bangladesh: results of a functionality survey. International Journal of Environmental Health Research 17, 207-218.

Lam, S.-P., 2006. Predicting intention to save water: theory of planned behavior, response efficacy, vulnerability and perceived effectiveness of alternative solutions. Journal of Applied Social Psychology 36, 2803-2824.

Martin, I.M. Bender, H., Raish, C., 2007. What motivates individuals to protect themselves from risks: the case of wildland fires. Risk Analysis 27, 887-900.

Moser, S., Mosler, H.-J., 2008. Differences in influence patterns between groups predicting the adoption of a solar disinfection technology for drinking water in Bolivia. Social Science and Medicine 67, 497-504.

Mosler, H.-J., Martens, T., 2008. Designing environmental campaigns by using agent-based simulations: strategies for changing environmental attitudes. Journal of Environmental Management 88, 805-816.
Opar, A., Pfaff, A., Seddique, A.A., Ahmed, K.M., Graziano, J.H., van Geen, A., 2007. Responses of 6500 households to arsenic mitigation in Araihazar, Bangladesh. Health and Place 13, 164-172.

Paul, B.K., 2004. Arsenic contamination awareness among the rural residents in Bangladesh. Social Science and Medicine 59, 1741-1755.

Rogers, E.M., 2003. Diffusion of Innovations, fifth ed. Free Press, New York

Rogers, R.W., Prentice-Dunn, S., 1997. Protection motivation theory. In: Gochman, D.S. (Ed.), Handbook of Health Behavior Research I: Personal and Social Determinants. Plenum Press, New York, pp. 113-123.

Schwarzer, R., 2008. Modeling health behavior change: how to predict and modify the adoption and maintenance of health behaviors. Applied Psychology: An International Review 57, 1-29.

Severtson, D.J., Baumann, L.C., Brown, R.L., 2006. Applying a health behavior theory to explore the influence of information and experience on arsenic risk representations, policy beliefs, and protective behavior. Risk Analysis 26, 353-368.

Shaw, W.D., Walker, M., Benson, M., 2005. Treating and drinking well water in the presence of health risks from arsenic contamination: results from a U.S. hot spot. Risk Analysis 25, 1531-1543.

Smith, A.H., Lingas, E.O., Rahman, M., 2000. Contamination of drinking-water by arsenic in Bangladesh: a public health emergency. Bulletin of the World Health Organization 78, 1093-1103.

Van Geen, A., Ahsan, H., Horneman, A.H., Dhar, R.K., Zheng, Y., Hussain, I., et al. 2002. Promotion of well-switching to mitigate the current arsenic crisis in Bangladesh. Bulletin of the World Health Organization 80, 732-737.

Von Brömssen, M., Jakariya, M., Bhattacharya, P., Ahmed, K.M., Hasan, M.A. Sracek, O., et al., 2007. Targeting low-arsenic aquifers in Matlab Upazila, Southeastern Bangladesh. Science of the Total Environment 379, 121-132.

Wasserman, G.A., Liu, X., Parvez, F., Ahsan, H., Factor-Litvak, P., van Geen, A., et al. 2004. Water arsenic exposure and children's intellectual function in Araihazar. Bangladesh. Environmental Health Perspectives 112, 1329-1333.

Weinstein, N.D., 1988. The precaution adoption process. Health Psychology 7 $355-386$.

WHO, 2001. Arsenic in drinking water. Fact sheet number 210. Available from: chttp://www.who.int/mediacentre/factsheets/fs210/en/print.html> (accessed 24.01.08).

WSP and UNICEF, 2007. Improving household drinking water quality. Use of ceramic water filters in Cambodia. Available from: <http://www.wsp.org/ UserFiles/file/926200724252_eap_cambodia_filter.pdf > (accessed 25.01.09). 